
\title{
3 Research Square \\ The Effect of Serum Protein on Enterococcus Faecalis Adhesion to Three types of Root Sealers and Gutta-Percha
}

\section{Xinwei Lin}

Department of Operative Dentistry and Endodontics, Guanghua school of stomatology, Sun Yat-sen University

\section{Danlu Chi}

Department of Operative Dentistry and Endodontics, Guanghua school of stomatology, Sun Yat-sen University

\section{Qimei Gong}

Department of Operative Dentistry and Endodontics, Guanghua school of stomatology, Sun Yat-sen University

\section{Zhongchun Tong ( $\nabla$ tongzhch@mail.sysu.edu.cn )}

Department of Operative Dentistry and Endodontics, Guanghua school of stomatology, Sun Yat-sen University https://orcid.org/0000-0003-2950-4969

\section{Research article}

Keywords: Enterococcus faecalis, root canal sealers, fetal bovine serum

Posted Date: May 6th, 2021

DOI: https://doi.org/10.21203/rs.3.rs-493090/v1

License: (c) (1) This work is licensed under a Creative Commons Attribution 4.0 International License. Read Full License 


\section{Abstract}

The aim of this study was to evaluate the effect of serum protein on Enterococcus faecalis adhesion and survival on the surface of Apexit Plus (AP), AH-Plus (AH), a tricalcium silicate-containing sealer (Iroot $\mathrm{SP}$ ) and gutta-percha (GP). AP, AH or Iroot SP was evenly coated on GP. After root sealers setting, the amount of $E$. faecalis adhering to the sealers was evaluated in fetal bovine serum (FBS) or TSBG medium by viable cell plate counts. The morphology of the sealers coated on GP and 7-day-old E. faecalis biofilm was observed by scanning electron microscopy (SEM). Furthermore, the ratios of viable and dead cells in biofilm were calculated by a Carl Zeiss confocal laser scanning microscope (CLSM) and ZEN software. In 1 and 7 days of assays, the amount of $E$. faecalis adhering to the surface of sealers or GP in FBS was significantly less than in TSBG $(P<.05)$. FBS more significantly reduced the bacterial amount on the SP and GP than on the AP and AH. E. faecalis biofilm on the AP and SP were more typical in the TSBG than in the FBS. The ratio of viable cell in the E. faecalis biofilm was the lowest on the SP by CLSM. It can be stated that Apexit Plus, AH-Plus and Iroot SP sealers may provide the substrate for $E$. faecalis adhesion, and the serum proteins significantly influenced bacterial adhesion to the surface of Apexit Plus, AH-Plus, Iroot SP and gutta-percha.

\section{Introduction}

Adequate root canal obturation prevents bacterial invasion of the root canal space and is one of the key factors in successful endodontic treatment [1]. Although chemomechanical preparation and medicaments may remove the most pathogenic bacteria in the root canal system, some areas, such as isthmuses, lateral canals, accessory canals, and other root canal irregularities, remain untouched [2]. The untouched areas may contain some bacteria and prevent the healing of periradicular lesions. In root canal obturation, endodontic sealers may entomb residual bacteria and act as disinfectants to prevent bacterial invasion $[3,4]$.

The current types of endodontic sealers for clinical use were categorized as zinc oxide-eugenol, epoxy resin, tricalcium silicate, fatty acid, glass ionomer, and methacrylate resin sealers, among others, according to their reaction type, composition, and properties [3]. Many endodontic sealers possess antimicrobial activity against a range of common pathogenic microbes and provide a complete microscopic seal to impede bacterial invasion of the root canal system [3,5-7]. However, gutta-percha points enclosed by endodontic sealers may still provide substrate for bacterial adhesion despite their antibacterial activities. The extraradicular presence of the filling material may delay healing of periradicular diseases or even cause treatment failure [8-10].

Gutta-percha and sealers are generally well tolerated with apical tissues in the absence of concomitant infection, and even at the existence of filling material extrusion, histological healing may still occur [11, 12]. However, in the presence of extrusion of infected debris by overinstrumentation or infection involved in the periradicular tissues, the extruded gutta-percha and sealers may serve as a biofilm reservoir for sustained infection at the periradicular area, which might contribute to nonhealing outcome [13]. 
Enterococcus faecalis species were considered to be the predominant bacteria in root-filled teeth with therapy failure. Some studies indicated that $E$. faecalis and bacterial biofilms were found on gutta-percha filling materials obtained from teeth associated with refractory radicular periodontitis [14-16]. At present, studies on bacterial adhesion to endodontic sealers as well as the antibacterial activities of sealers have been evaluated in common bacterial culture medium [16-18]. However, the extruded gutta-percha and sealer in vivo are at the periradicular tissue. Therefore, there is a need for further investigation of the effect of serum protein on $E$. faecalis biofilm adhesion to the surface of gutta-percha coated with three common endodontic sealers, Apexit Plus, AH-Plus and a tricalcium silicate-containing sealer.

\section{Materials And Methods}

Enterococcus faecalis OG1RF was selected as the test bacteria in this study. A culture of the bacteria from the freezer $\left(-80^{\circ} \mathrm{C}\right)$ was streaked onto brain-heart infusion agar $(\mathrm{BHI}$; Difco Laboratories, Detroit, MI) plates and grown at $37^{\circ} \mathrm{C}$ for $24 \mathrm{~h}$. A single colony of bacteria was inoculated into $5 \mathrm{~mL}$ of BHI broth and cultured at $37^{\circ} \mathrm{C}$ under anaerobic conditions up to the exponential phase.

Three resin blocks with simulated curved root canals (Plastic Training Block V04 0245; VDW, Munich, Germany) were instrumented using a ProTaper system (Dentsply Maillefer, Ballaigues, Switzerland) up to F2 accompanied by irrigation with $3 \%$ sodium hypochlorite $(\mathrm{NaOCl})$ and $17 \%$ ethylenediaminetetraacetic acid (EDTA). The three prepared root canals were filled with $5.25 \% \mathrm{NaOCl}$ and disinfected for $10 \mathrm{~min}$. After being dried with sterile paper points, the three prepared root canals were filled with three sealers: Apexit Plus (Calcium hydroxide-based root canal sealer, Ivoclar Vivadent, Liechtenstein), AH-Plus (Dentsply De Trey GmbH, Konstanz, Germany) and Iroot SP (Tricalcium silicate-containing sealer, Innovative BioCeramix Inc., Vancouver, BC, Canada). After sterilization by soaking in $5.25 \% \mathrm{NaOCl}$ for 5 min, nine ProTaper F2 gutta-percha (GP) points were inserted into three groups of root canals filled with the sealer and rotated back and forth $360^{\circ}$ to ensure that the sealer was evenly coated on the surface of the GP. After the solidification of sealers, the GP with the sealer and the control GP without the sealer were cut off at the $10 \mathrm{~mm}$ site from the tip and placed in a 24-well microplate.

To evaluate the effect of the sealers on bacterial adhesion, $1.99 \mathrm{~mL}$ of TSB broth with $1 \%$ glucose (TSBG) and $10 \mu \mathrm{L}$ of $E$. faecalis at the exponential phase were added to a 24-well microplate and incubated at $37^{\circ} \mathrm{C}$ for up to 1 day or 7 days. The culture was replaced with fresh medium every second day. After incubation, the four groups of GP specimens were removed and washed two times with sterile phosphatebuffered saline (PBS) solution to remove the nonadhesive cells. The GP specimens were then placed in a centrifuge tube containing $2 \mathrm{~mL}$ of sterile PBS buffer and stored in an ice box. The adhesive bacteria were harvested by scrape and ultrasonic treatment and resuspended in PBS. Afterward, the bacterial suspension was consecutively diluted by 10 -fold steps and spread on $\mathrm{BHI}$ agar plates. The colonies were counted, and the amount of bacteria adhered to the four groups of GP was calculated. To evaluate the effect of serum protein on bacterial adhesion, the same four groups of GP were immersed in $1.99 \mathrm{~mL}$ of fetal bovine serum (FBS, HyClone, America) and $10 \mu \mathrm{L}$ of E. faecalis at the exponential phase, and the 
same bacterial adhesive assay was performed. Each test was carried out at least 3 times on a different day.

The three groups of GP specimens with the sealers and the control GP specimen without the sealer were prepared, and 7 days of $E$. faecalis adhesion in TSBG or FBS was completed according to the above procedure. The GP specimens were fixed in $2.5 \%$ glutaraldehyde and dehydrated in a series of acetonitrile solutions ( $50 \%, 70 \%, 80 \%$, and $90 \%$ for 20 min each and $100 \%$ for 20 min twice) after being rinsed twice with sterile PBS buffer. The specimens were dried and then sputtered with gold. The sealers and $E$. faecalis biofilm on the surface of GP were observed by scanning electron microscopy (SEM, E-1010, Hitachi, Ibaraki, Japan).

Apexit Plus, AH-Plus and Iroot SP sealers were evenly coated on the surface of a 10-mm diameter cover glass. After solidification at $37^{\circ} \mathrm{C}$, the cover glasses were immersed in FBS for $2 \mathrm{~h}$ in a 24 -well microplate. The cover glasses without sealers were referred to as the control. The four groups of cover glasses were transferred to another well, and $1.99 \mathrm{~mL}$ of TSBG and $10 \mu \mathrm{L}$ of $E$. faecalis at the exponential phase were added. After incubation at $37^{\circ} \mathrm{C}$ for 7 days, the bacterial biofilm on the surface of the sealers was gently washed twice with PBS. Subsequently, the cover glasses with bacterial biofilms were transferred to Petri dishes with glass bottoms (D: $35 \mathrm{~mm}$, Hangzhou Shengyou Biotechnology, China) and stained with syto 9 and propidium iodide $(\mathrm{PI})$ at room temperature in darkness for 15 min according to the specifications of the L7012 kit (LIVE/DEAD Bac-Light Bacterial Viability Kit; Molecular Probes, Eugene, OR). The Petri dishes were then clamped, and bacterial biofilm was scanned with a Carl Zeiss confocal laser scanning microscope (CLSM). SYTO 9 and PI were excited at $488 \mathrm{~nm}$ and $543 \mathrm{~nm}$, respectively. Three-dimensional biofilms were captured along the $Z$ axis. The ratio of viable and dead cells in the biofilm was calculated by ZEN software (ZEN 2012 light edition, Carl Zeiss Microlmaging, Inc., Thornwood, NY).

Statistical analysis was performed using SPSS 20.0 software. The numbers of $E$. faecalis adhesions on the surfaces of the three sealers and the control group were compared using one-way ANOVA and Tukey's HSD tests. A P value $<0.05$ was considered statistically significant.

\section{Results}

\section{The effect of the sealers on bacterial adhesion}

At both 1 day (Fig. 1a) and 7 days (Fig. 1b) of bacterial adhesion, the amount of E. faecalis adhering to the AP, SP and GP in TSBG was significantly greater than that in FBS $(P<.05)$, and $E$. faecalis adhesion to the AP was significantly greater than that to the SP and GP in FBS $(P<.05)$. However, the four groups exhibited no significant difference in TSB $(P>.05)$. E. faecalis adhesion to the AH was significantly greater than that to the SP and GP in FBS only in 7 days of group. Whether in FBS or in TSB, 7 days of $E$. faecalis adhesion were more than 1 day of adhesion in the four groups (Fig. 1). 


\section{Morphology of bacterial biofilm adhesion to the surface of the sealers and GP}

GP coated with AP, AH and SP were observed by SEM after being immersed in FBS and TSBG medium for 7 days. The few bacteria adhered to the SP and GP, and the mass of bacteria aggregated on the AP and $\mathrm{AH}$ in FBS medium (Fig. 2). In TSBG medium, a number of $E$. faecalis aggregated on the AP and SP and showed a typical biofilm structure (Fig. 3e and g). Few E. faecalis were adhered to the AH, and showed relatively loose (Fig. 3f). Furthermore, a few E. faecalis were dispersedly adhered to the GP, and did not form biofilm structure (Fig. 3h).

\section{The antibacterial acitivities of three root sealers on Enterococcus faecalis biofilm}

The images of 3-dimensional E. faecalis biofilms on the surface of sealers are shown in Fig. 4. For the control, E. faecalis biofilms mostly showed green live bacteria. The red dead bacteria were found on the surface of three sealers, and the percentages of dead bacteria on the SP sealer were the highest in the three groups of sealers.

\section{Discussion}

The filling materials should be restricted to the intraradicular space in root canal obturation, and endodontic treatment with root canal fillings ending within $2 \mathrm{~mm}$ of scope of the radiographic apex showed a high success rate [19]. However, the extrusion of root canal filling materials occasionally occurs due to incorrect operations, anatomical factors, and material properties, among others. Extruded filling materials may affect the treatment outcome, and a significantly worse outcome was observed for teeth with apical periodontitis in comparison with teeth with no lesions [12]. Extrusion might not only cause an inflammatory response but also provide a substrate for bacterial adhesion [20, 21]. Although filling sealers have antibacterial activities, some bacteria, such as $E$. faecalis, still adhere to the surface of the materials [16, 22]. Our studies also indicated that E. faecalis may survive on the surface of Apexit Plus, AH-Plus, tricalcium silicate-containing sealer, and gutta-percha. The substrate of overfilling may be conducive to the formation of bacterial biofilms and further hinder the healing of apical periodontitis.

The antibacterial activities of filling sealers against $E$. faecalis were mostly measured by bacterial growth in common medium [5, 23-25]. In the different tests, the sealers showed different antibacterial activities. A study by Bukhari et al.[5] showed that Endosequence BC sealer (the same sealer as Iroot SP, marketed under different brand names) killed significantly more 8-week-old E. faecalis in biofilms attached to the canal surfaces when compared with AH-plus by confocal laser scanning microscopic analysis. Candeiro et al. [21] showed no bacterial growth from $24 \sim 168 \mathrm{~h}$ in the medium after the insertion of $\mathrm{AH}$-plus or BC sealer by a direct contact test (DCT). In the antibacterial activities of sealers, DCT is often employed. However, when the sealers or gutta-percha overfilled into the periradicular tissues, the amount of bacteria 
adhered to the sealers was not tested only by DCT due to the existence of the tissue fluid. The effect of the proteins in tissue fluid on the antibacterial activities of the drugs in vivo was evaluated by using FBS, human serum and BSA [26-28]. When the extruded materials exist in the periradicular tissues, the antibacterial action of the sealers may not be the same as the in vitro test in the bacterial medium. Our studies showed that the amount of $E$. faecalis adhering to the three sealers and gutta-percha was lower in FBS than in TSB, and the effect of FBS on the antibacterial activities of SP was more significant than that of $\mathrm{AP}$ or $\mathrm{AH}$. The amount of bacteria adhering to the SP was reduced more significantly in the FBS medium than in the TSB medium.

The amount of E. faecalis adhering to AH significantly decreased in FBS for one day, and the bacterial amount increased for 7 days, which was consistent with the Kapralos et al. study. Despite the different test methods, E. faecalis tested on the surface of the sealers coated on gutta-percha in our studies or $E$. faecalis count by a modified DCT assay in the Kapralos et al. study, both AH Plus had high antibacterial activity on one day, and the antibacterial activity decreased on 7 days [7]. The viable E. faecalis amount was reduced on the surface of SP compared to that of AH-plus on day 7, which indicated that the bioceramic sealers showed durable antibacterial activities against $E$. faecalis. The freshly mixed sealers were often considered to have positive antimicrobial activity against $E$. faecalis, and the antimicrobial activity was lost as the material set except the bioceramic sealers [29].

Gutta-percha is the most popular core material used for root obturation. In our study, few E. faecalis adhered to the gutta-percha without sealers in the presence of FBS, which suggested that the extruded gutta-percha alone may not be a favorable substrate for bacterial adhesion. The amount of bacteria adhesion after 7 days was the least on the gutta-percha alone in the four test groups. The relatively smooth surface of gutta-percha did not benefit bacterial adhesion. Gutta-percha cones consist of approximately $20 \%$ guttapercha, $65 \%$ zinc oxide, $10 \%$ radiopacifiers, and $5 \%$ plasticizers, and more attempts have been made to make gutta-percha antimicrobial by the addition of antibacterial materials [30-33], which further decreased bacterial adhesion. The results indicated that gutta-percha extrusion alone might not be a main factor for periapical reinfection.

\section{Conclusion}

Despite the antibacterial action of Apexit Plus, AH-Plus and Iroot SP sealers, E. faecalis may still adhere to the surface of the three sealers coated on gutta-percha. Serum protein significantly influenced bacterial adhesion to the sealers. FBS reduced the amount of $E$. faecalis adhering to the three sealers, and the effect of FBS on the antibacterial activities of Iroot SP was more significant than that of Apexit Plus and AH-Plus. The gutta-percha without the sealer coating was not helpful for $E$. faecalis adhesion in the presence of the serum protein.

\section{Declarations}

\section{Acknowledgements}


This study was supported by the National Natural Science Foundation of China (grant no. 81870750) and Guangdong Financial Fund for High-Caliber Hospital Construction (174-2018-XMZC-0001-03-0125/C-5).

\section{Conflict of interest}

The authors declare that they have no conflict of interest.

\section{References}

1. Donnermeyer D, Vahdat-Pajouh N, Schafer E, Dammaschke T. Influence of the final irrigation solution on the push-out bond strength of calcium silicate-based, epoxy resin-based and silicone-based endodontic sealers. Odontology. 2019;107(2):231-6.

2. Nosrat A, Verma P, Hicks ML, Schneider SC, Behnia A, Azim AA. Variations of Palatal Canal Morphology in Maxillary Molars: A Case Series and Literature Review. J Endod. 2017;43(11):1888-96.

3. Komabayashi T, Colmenar D, Cvach N, Bhat A, Primus C, Imai Y. Comprehensive review of current endodontic sealers. Dent Mater J. 2020;39(5):703-20.

4. Salz U, Poppe D, Sbicego S, Roulet JF. Sealing properties of a new root canal sealer. Int Endod J. 2009;42(12):1084-9.

5. Bukhari S, Karabucak B. The Antimicrobial Effect of Bioceramic Sealer on an 8-week Matured Enterococcus faecalis Biofilm Attached to Root Canal Dentinal Surface. J Endod. 2019;45(8):104752.

6. Dental S, Gallusi G, Campanella V, Montemurro E, Di Taranto V, Libonati A. Antibacterial activity of first and latest generation bioceramic sealers on the elimination of enterococcus faecalis: An in vitro study. J Biol Regul Homeost Agents. 2020;34(3 Suppl. 1):73-9.

7. Kapralos V, Koutroulis A, Orstavik D, Sunde PT, Rukke HV. Antibacterial Activity of Endodontic Sealers against Planktonic Bacteria and Bacteria in Biofilms. J Endod. 2018;44(1):149-54.

8. Molven O, Halse A, Fristad I, MacDonald-Jankowski D. Periapical changes following root-canal treatment observed 20-27 years postoperatively. Int Endod J. 2002;35(9):784-90.

9. Nair PN, Sjogren U, Krey G, Sundqvist G. Therapy-resistant foreign body giant cell granuloma at the periapex of a root-filled human tooth. J Endod. 1990;16(12):589-95.

10. Sjogren U, Sundqvist G, Nair PN. Tissue reaction to gutta-percha particles of various sizes when implanted subcutaneously in guinea pigs. Eur J Oral Sci. 1995;103(5):313-21.

11. Fristad I, Molven O, Halse A. Nonsurgically retreated root filled teeth-radiographic findings after 20-27 years. Int Endod J. 2004;37(1):12-8.

12. Ricucci D, Rocas IN, Alves FR, Loghin S, Siqueira JF, Jr. Apically Extruded Sealers: Fate and Influence on Treatment Outcome. J Endod. 2016;42(2):243-9.

13. Bjorndal L, Amaloo C, Markvart M, Rud V, Qvortrup K, Stavnsbjerg C, et al. Maxillary Sinus Impaction of a Core Carrier Causing Sustained Apical Periodontitis, Sinusitis, and Nasal Stenosis: A 3-year 
Follow-up. J Endod. 2016;42(12):1851-8.

14. Guerreiro-Tanomaru JM, de Faria-Junior NB, Duarte MA, Ordinola-Zapata R, Graeff MS, TanomaruFilho M. Comparative analysis of Enterococcus faecalis biofilm formation on different substrates. $J$ Endod. 2013;39(3):346-50.

15. Noiri Y, Ehara A, Kawahara T, Takemura N, Ebisu S. Participation of bacterial biofilms in refractory and chronic periapical periodontitis. J Endod. 2002;28(10):679-83.

16. Senges C, Wrbas KT, Altenburger M, Follo M, Spitzmuller B, Wittmer A, et al. Bacterial and Candida albicans adhesion on different root canal filling materials and sealers. J Endod. 2011;37(9):1247-52.

17. Huang Y, Li X, Mandal P, Wu Y, Liu L, Gui H, et al. The in vitro antimicrobial activities of four endodontic sealers. BMC Oral Health. 2019;19(1):118.

18. Alsubait S, Albader S, Alajlan N, Alkhunaini N, Niazy A, Almahdy A. Comparison of the antibacterial activity of calcium silicate- and epoxy resin-based endodontic sealers against Enterococcus faecalis biofilms: a confocal laser-scanning microscopy analysis. Odontology. 2019;107(4):513-20.

19. Schaeffer MA, White RR, Walton RE. Determining the optimal obturation length: a meta-analysis of literature. J Endod. 2005;31(4):271-4.

20. Yoshino P, Nishiyama CK, Modena KC, Santos CF, Sipert CR. In vitro cytotoxicity of white MTA, MTA Fillapex(R) and Portland cement on human periodontal ligament fibroblasts. Braz Dent J. 2013;24(2):111-6.

21. Candeiro GTM, Moura-Netto C, D'Almeida-Couto RS, Azambuja-Junior N, Marques MM, Cai S, et al. Cytotoxicity, genotoxicity and antibacterial effectiveness of a bioceramic endodontic sealer. Int Endod J. 2016;49(9):858-64.

22. Xu J, He J, Shen Y, Zhou X, Huang D, Gao Y, et al. Influence of Endodontic Procedure on the Adherence of Enterococcus faecalis. J Endod. 2019;45(7):943-9.

23. Beyth N, Kesler Shvero D, Zaltsman N, Houri-Haddad Y, Abramovitz I, Davidi MP, et al. Rapid kill-novel endodontic sealer and Enterococcus faecalis. PLoS One. 2013;8(11):e78586.

24. Bodrumlu E, Semiz M. Antibacterial activity of a new endodontic sealer against Enterococcus faecalis. J Can Dent Assoc. 2006;72(7):637.

25. Hoelscher AA, Bahcall JK, Maki JS. In vitro evaluation of the antimicrobial effects of a root canal sealer-antibiotic combination against Enterococcus faecalis. J Endod. 2006;32(2):145-7.

26. Tong Z, Zhang Y, Wei X. The effect of human serum and dentin powder alone or in combination on the antibacterial activity of sodium hypochlorite against Enterococcus faecalis. Arch Oral Biol. 2019;97:72-76.

27. Pappen FG, Qian W, Aleksejuniene J, Leonardo Rde T, Leonardo MR, Haapasalo M. Inhibition of sodium hypochlorite antimicrobial activity in the presence of bovine serum albumin. J Endod. 2010;36(2):268-71.

28. Crabbe A, Liu Y, Matthijs N, Rigole P, De La Fuente-Nunez C, Davis R, et al. Antimicrobial efficacy against Pseudomonas aeruginosa biofilm formation in a three-dimensional lung epithelial model 
and the influence of fetal bovine serum. Sci Rep. 2017;7:43321.

29. AlShwaimi E, Bogari D, Ajaj R, Al-Shahrani S, Almas K, Majeed A. In Vitro Antimicrobial Effectiveness of Root Canal Sealers against Enterococcus faecalis: A Systematic Review. J Endod. 2016;42(11):1588-97.

30. Chogle S, Mickel AK, Huffaker SK, Neibaur B. An in vitro assessment of iodoform gutta-percha. J Endod. 2005;31(11):814-6.

31. Lohbauer U, Gambarini G, Ebert J, Dasch W, Petschelt A. Calcium release and pH-characteristics of calcium hydroxide plus points. Int Endod J. 2005;38(10):683-9.

32. Lui JN, Sae-Lim V, Song KP, Chen NN. In vitro antimicrobial effect of chlorhexidine-impregnated gutta percha points on Enterococcus faecalis. Int Endod J. 2004;37(2):105-13.

33. Melker KB, Vertucci FJ, Rojas MF, Progulske-Fox A, Belanger M. Antimicrobial efficacy of medicated root canal filling materials. J Endod. 2006;32(2):148-51.

\section{Figures}

a

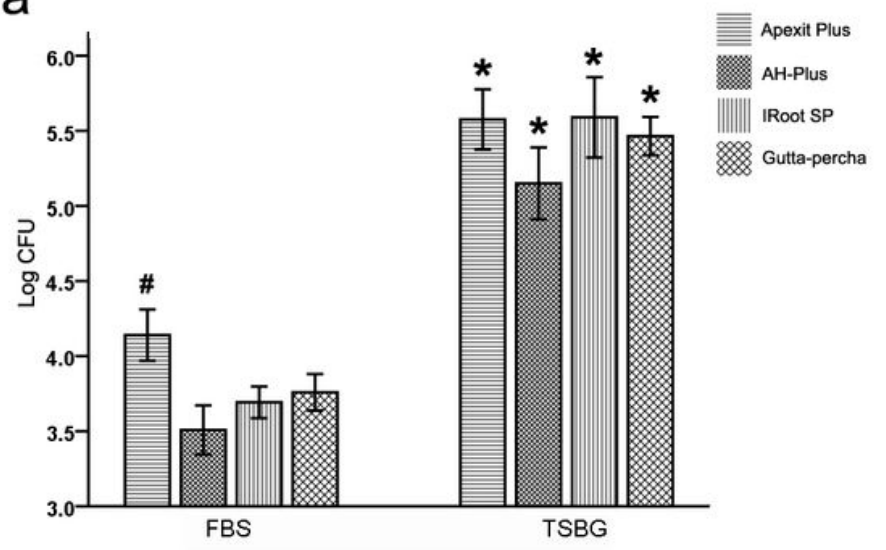

b

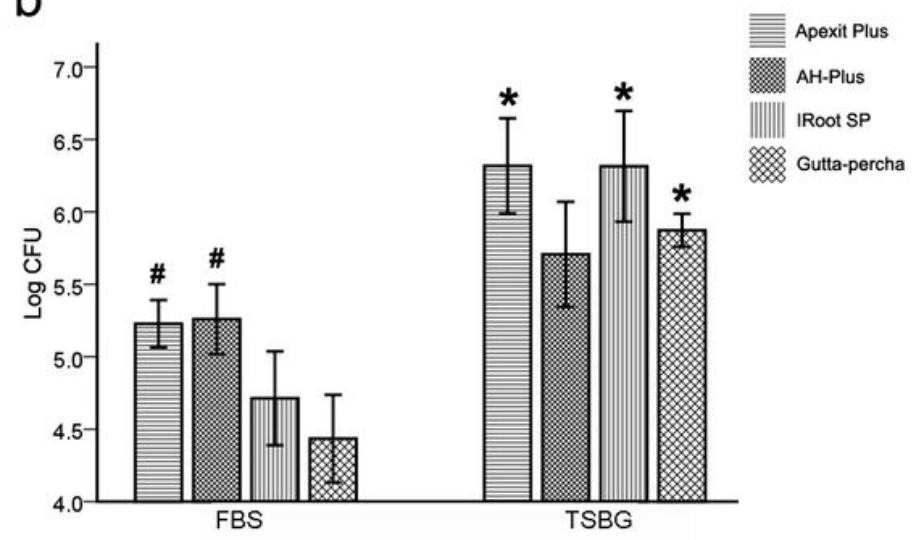

\section{Figure 1}

The amount of E. faecalis adhering to the AP, AH, SP and GP in FBS or TSBG medium for 1 day (a) and 7 days (b). "\#" represents a significant difference between the amount of E. faecalis adhering to the AP and GP $(P<.05)$. "*" represents a significant difference between the amount of $E$. faecalis adhering to the same sealer in FBS and TSBG medium $(P<.05)$. 

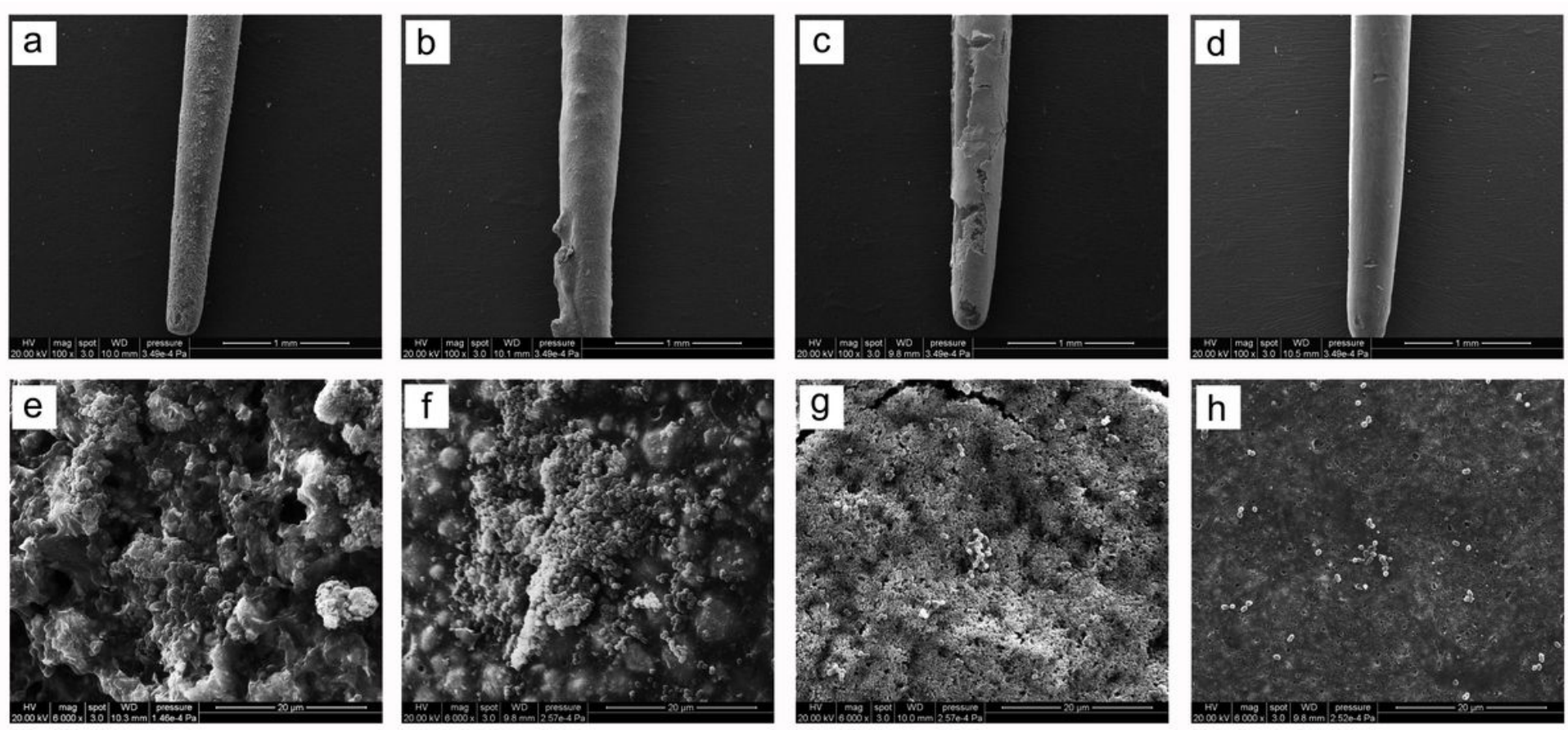

Figure 2

E. faecalis adhesion to Apexit Plus (AP) (a) and (e), AH-Plus (AH) (b) and (f), tricalcium silicatecontaining sealer (SP) (c) and (g), and gutta-percha (GP) points (d) and (h) in FBS medium. (a d) were at 100 magnification; (e h) were at 6000 magnification.
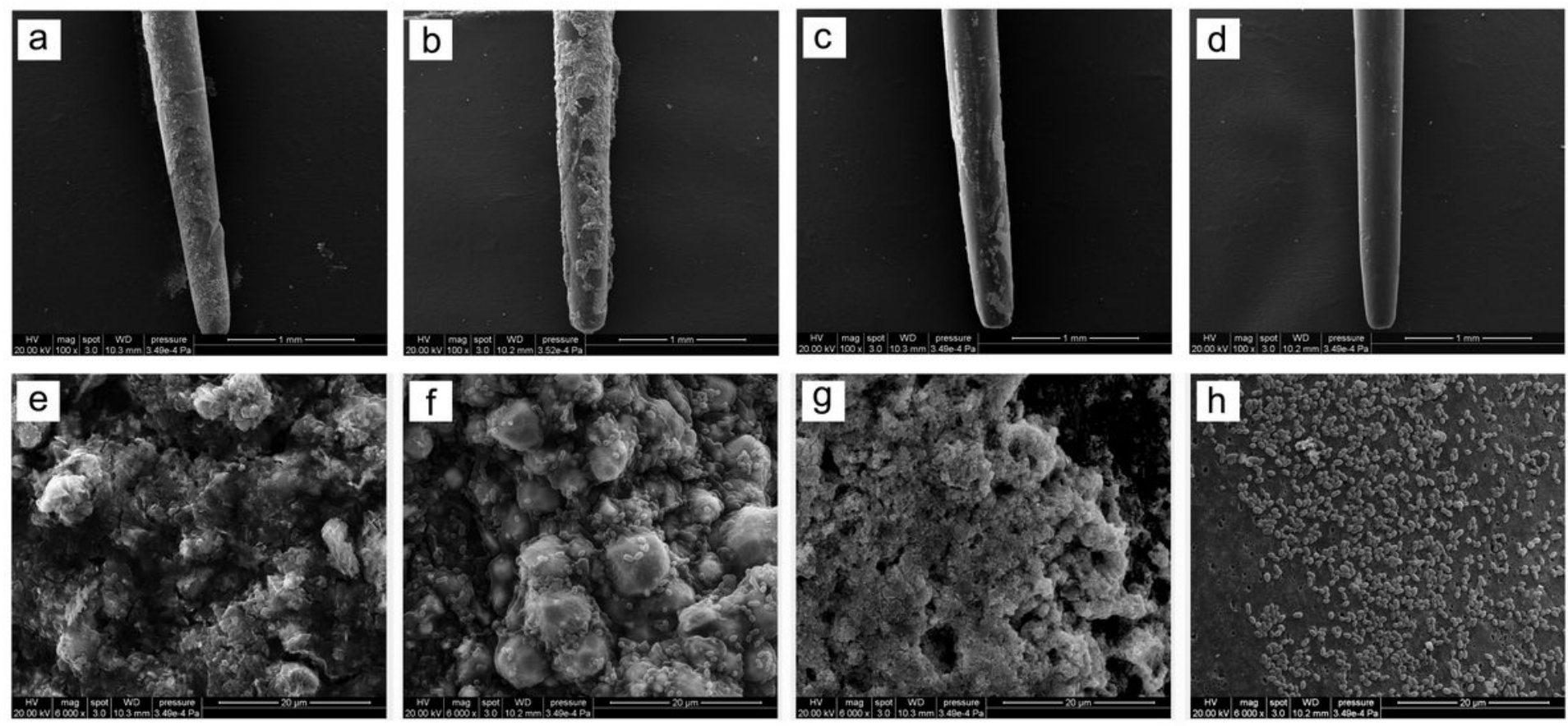

\section{Figure 3}

E. faecalis adhesion to the surface of Apexit Plus (AP) (a) and (e), AH-Plus (AH) (b) and (f), tricalcium silicate-containing sealer (SP) (c) and (g), and Gutta-percha (GP) points (d) and (h) in the TSBG medium. 
(a d) were at 100 magnification; (e h) were at 6000 magnification.
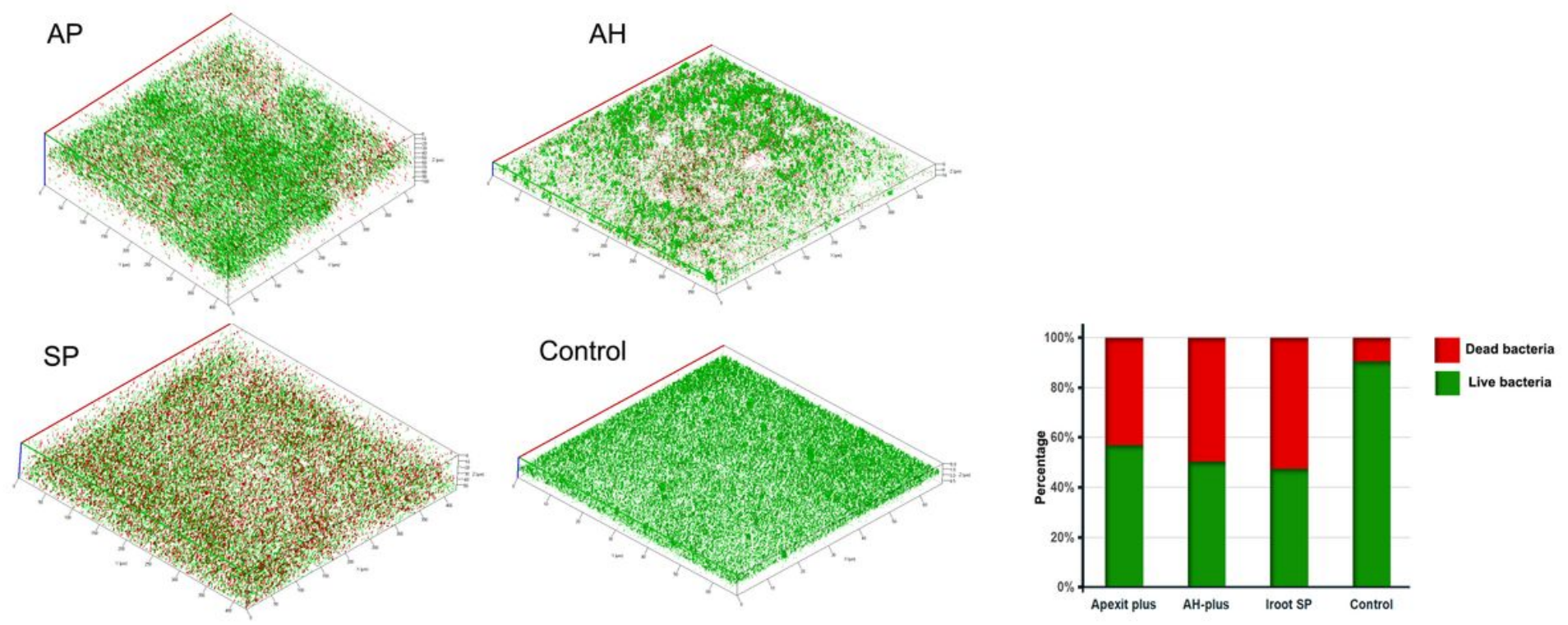

Figure 4

CLSM images of 3-dimensional E. faecalis biofilms on the surface of Apexit Plus (AP), AH-Plus (AH), a tricalcium silicate-containing sealer (SP) and the control without the sealer. Dead cells were stained red, while live cells were stained green in biofilm using the LIVE/DEAD Bac-Light Bacterial Viability L7012 Kit. The percentages of live and dead bacteria in 3-dimensional E. faecalis biofilms were calculated by ZEN 2012 software. 